regulations for the Fellowship of the Royal College of surgeons. At present students of medicine enter with the idea of obtaining a qualification; many of them without any idea beyond qualifying. A large number of students enter together and after a while the teachers are able to say which of those men are likely to prove better than their fellows. At this critical time a student can best be advised as to his future career, and in surgery the course is simple. He is advised after passing the second examination of the Conjoint Board to devote a further year of study to anatomy and physiology and then to pass the primary fellowship examination, which means a great deal of extra and very hard work. This advice is generally taken and with good results. If, on the other hand, the desire is to take a higher standard in medicine great difficulties are in the way. The student, perhaps, has not matriculated, or if he has matriculated has not taken the preliminary scientific, and in nine such cases out of ten he is compelled to say that he cannot go back to these earlier studies, the loss of time being too serious to contemplate. If, however, the second examination of the Conjoint Board were allowed to stand as at present with a proviso that all students having passed that examination be allowed to proceed for higher degrees, keeping the standard for the higher examinations at the same level as at present, there would be, I think, a very large increase in the number of students proceeding for the degrees of the University of London. It might be objested that no student would then take the preliminary scientific examination. This, however, need not be so. Students should be directly encouraged to take this in the usual way, and the intermediate examination for those who have not passed in the subjects of the preliminary examination might be made to include it. That is to say, students proceeding for the intermediate M. B. examination under the above proviso should be required to take chemistry and physics and biology as extra subjects, the examination being divided into two parts for that purpose.

Of course, it would simplify matters very much if everyone who was qualified was called "doctor." As a matter of fact everybody who qualifies is called "doctor" generally and a very large number of the public fail to understand the difference between the medical attendant who has obtained a degree and the medical attendant who has been satisfied with diplomas, and even those who are behind the scenes know that not infrequently the better man of the two is the man who has not taken degrees. After all it is not desirable that every practitioner should be of the highest rank. There must be the more ordinary class to attend the poorer part of the population, and if it could be so arranged that the Royal Colleges, with the Apothecaries Society included, should have the power of joining together for one final examination with which the ordinary practitioner would be contented, then those who desired higher distinction could proceed for the degrees of the University. By doing this a one-portal examination in London would be established.-I am, Sirs, yours faithfully,

MuNRo SCO'Tt,

Warden, London Hospital Medical College.

\section{THE INCORPORATION OF UNIVERSITY COLLEGE, LONDON, IN THE UNIVERSITY OF LONDON.}

\section{To the Editors of THE LANCET.}

SIRs,-The policy of the incorporation of University College in the University of London has met with general approval as an important step in the direction of establishing in London a real teaching university which shall have its own professors, laboratories, buildings, and equipment. For the purposes of incorporation a sum of $\$ 92,000$ has already been subscribed. A further sum of $£ 108,000$ still remains to be raised in order to place the medical school of University College on a proper footing and to transfer University College School to a more suitable quarter of London and thus to satisfy the demand that exists in the suburbs of London for secondary education of the first grade. This sum of $£ 108,000$ includes the estimated cost of a new site for the school of advanced medical studies which it is found desirable to provide in order to avoid encroaching on the ground which it is proposed to place at the disposal of the University for the further extension of University buildings.
The University and the College are both equally interested in speedily obtaining the money that is still required, and in view of the important issues involved it cannot be considered that the total sum asked for is a large one. We appeal with confidence to those who are aware of the needs of London in respect of university education to assist in carrying out the proposed incorporation. Subscriptions should be sent addressed to Sir Richard Farrant (University College, London, Gower-street, W.C.), who will be glad to supply any information desired.

We are, Sirs, your obedient servants,

REAY,

President of the College;

BRASSEY,

Chairman of the Appeal Committee; RICHARD FARRANT,

Treasurer of the College.

University College, London, Nov. 7th, 1902.

\section{THE TREATMENT OF THE SUMMER DIARRHCEA OF INFANTS.}

To the Editors of $\mathrm{TH} \mathrm{E}$ L.NCET.

SIns, - In 'THE LANCET of Nov. 8th, p. 1284, you print a letter on the Treatment of the Summer Diarrhoea of Infants from the pen of Dr. J. Gordon Sharp of Leeds, in which he speculates on the connexion between thrush and summer diarrhœa. In a small book published in January, 1897, entitled "Intestinal Intoxication in Infants" (Rebman and Co.), will be found an account of some interesting clinical and bacteriological experiments carried out by me to ellicidate the afore-mentioned connexion. In this work also will be found all the materials of Dr. Sharp's communication systematised as a whole. There is one other factor in the causation of summer diarrhcea in infants which undoubtedly plays quite as great a part in its causation as thrush, and that is the deficiency of chlorides in the infantile circulation, particularly in hand-fed infants.

Professor A. E. Wright of Netley, than whom no one has done more valuable work in the department of chemical hæmology, has placed us in possession of sound practical data both for the prevention and cure of infantile diarrhcea in every phase of its existence as met with in ordinary practice. Professor Wright in his contributions to THE LANCET in 1897 on Coagulability of the Blood goes fully into the subject of chlorides, and adduces matter of the greatest value if applied to the study of infantile diarrhcea. Ballard showed that infantile diarrhcea depended mainly on the temperature of the earth and that when the thermometer at a depth of four feet registered $56^{\circ} \mathrm{F}$. in summer then infantile diarrhœea was at its highest incidence. This theory for long was held as the cause; we now know that it is compatible with every rational explanation of the causation of this disease by other agencies. To put the matter shortly, when the temperature of the soil had reached Ballard's point, then the day and night temperature showed little fluctuation; consequently, bacterial growth was least impeded and was therefore most noxious. The dry heat tended to cause free passage of water-carried chlorides out of the blood of infants through their skin and kidneys even in cases where chlorides were not administered in the food. The result was a fall of the coagulation index of the blood and serous hæmorrhage as a consequence ; this tended to remove more chlorides and so a vicious cycle was set up. Deficiency of chlorides also neans deficiency of hydrochloric gastric acidity, which is nature's barrier to the access of germs whose habitat and origin are the filthy surroundings of some infants. This access is also facilitated by the excess of alkaline mucus in the stomach of an infant the subject of hypochlorhydria, and so lactic, butyric, and other fermentative processes gain the upper hand. 'This latter leads to the oidium albicans gaining access to the intestines and its subsequent appearance at the anus and its cultivation from the nates as described by me in my experiments.

Dr. Sharp is to be thanked for his efforts to call attention briefly and simply to a practical method of dealing with this scourge, yet one cannot help thinking that till diseases of children are a separate item in the curriculum of every medical student we will make little headway in the diffusion of the necessary information. In my contribution to the literature on the subject, based on actual work personally undertaken during many years, I made an attempt to reduce the subject of infantile diarrhoea in the department of its pathology, bacteriology, clinical history, hygiene, and 
treatment by drugs and diet to a practical basis; that is, judged from the standpoint of the success which attended and continues to attend treatment based on those lines, which are practically identical with, and are an elaboration of, Dr. Sharp's experiences.

I am, Sirs, yours faithfully,

F. W. Forbes Ross, M.D. Edin., D.P. H. Lond. Gower-street, London, W.C., Nov. 9th, 1902.

\section{THE MEDICAL DEFENCE UNION.}

\section{To the Editors of THE LANCET.}

SIRs,--In answer to Mr. Percy Rose I have to state that the matter of imposing an entrance fee to all new subscribers to the Medical Defence Union joining on and after Jan. 1st, 1903 , is not one for discussion by the members at the annual meeting as the power to impose such entrance fee is granted to the council alone by the articles of association. 'To raise the subscription is a matter requiring the consent of members at a general meeting assembled, but the entrance fee is one solely for council to decide. The payment required including the entrance fee is so small and the benefits which may be derived should occasion require are so large that it is impossible to imagine that the amount to be asked for on and after Jan. 1st will prevent men from insuring. Considering that all medical societies of any note charge $£ 11 s$. per annum for the privilege of "discussion and hearing papers," 10s. a year for membership of the Medical Defence Union is very little. I may mention that the entrance fee was decided upon by the council after long and careful consideration and that the notice given is more than ample for every member of the profession in Great Britain and Ireland to apply for membership of the Union before Jan. 1st, 1903, on the old terms.

I am, Sirs, yours faithfully,

A. G. BAteman, General Secretary.

Trafalgar-square, W.C., Nov. 10th, 1902.

\section{DEATH UNDER CHLOROFORM. \\ To the Editors of THE LANCET.}

Sirs,-In the fatal case after chloroform which occurred at Guy's Hospital on Oct. 23rd the statement was made that the patient had only been given one and a half drachms of the anæsthetic. This shows that the death was not due to an excessive amount of chloroform having been administered. In a very able paper published last year Sir W. Mitchell Banks of Liverpool pointed out that the path of safety lay in following out the dictum, "Plenty of air, plenty of chloroform." This advice is not being followed in many quarters and professional anæsthetists are wasting their ingenuity in seeing by how little chloroform they can accomplish their end. Every physiologist knows that the brain cells require a constant supply of oxygen as they are unable to keep a store of it locked up for any considerable time, being rather unstable. Now, in order to accomplish anæsthesia on a minimum of chloroform the supply of oxygen must be curtailed very much. The fad for this accurate measurement of chloroform is ridiculous for another reason-namely, that a healthy baby will often take as much as a full-grown person.

\section{I am, Sirs, yours faithfully}

A. W. FULLER, M. B. Edin., \&c.

Royal Hospital for Children and Women, S.E., Oct. 25th, 1902.

** Our correspondent has overlooked an important point among others. All familiar with the action of chloroform are aware that a drachm or far less given without adequate dilution will cause death. Sir W. Mitchell Banks's dictum, which is almost a verbal repetition of Syme's, refers solely to the wholly untrustworthy method unhappily still commonly employed and called the "open method." Death from chloroform arises from the action of that drug upon the nervous tissue of the medullary centres and not from deprivation of oxygen, although nerve tissues the oxygen tension of which is lowered are more prone to chloroform destruction. The "fad" for accurate measurement of chloroform is on a parity with the attempt among all truly scientific persons to know what quantities of powerful poisons they are using in order that they may graduate their doses to the requirement of their patient. We have yet to meet the baby who, if accurately chloroformed, will require as much as a full-grown person.-ED. L.

\section{THE ROYAL MEDICAL BENEVOLENT COLLEGE. \\ To the Editors of THE LANCET.}

SIRs,--With reference to Dr. C. Holman's appeal on behalf of the above the following may seem to you not without interest to the profession at large. Some three years ago I was asked to fill the post of honorary local secretary in a district with some 70,000 inhabitants. I wrote to all medical men in the district whose names could be ascertained, and to some of the leading inhabitants of all denominations, urging the need of support, some 60 to 70 letters in all. With the exception of two or three letters of regret from personal medical friends I had no replies whatever. The following year I wrote to medical men only, personally known to me, asking for a donation or subscription of $5 s$.; two verbal expressions of regret.

Is not the apathy of medical men in this matter due to the overcrowded state of this as of all other callings? In suburban practice, when every newly qualified diplomate is Dr. - - physician and surgeon, and many are ready to undertake the medical care of a family of four at $9 d$. a month, we cease, as a class, to deserve to be called professional and become commercial. Hence, while we cultivate a cutting trade, we forfeit the status of our forefathers and correspondingly sink in the estimation of the public, our relation with our patients becomes purely on a trade basis. Why should they support a medical benevolent fund? On the other side many medical men finding their hand forced are obliged to meet competition, they do more work for less return and have no longer means to help.

Your return of new entries at medical schools shows a decided decrease, and it is a well-known fact that many medical men have within the last few years given up general practice for dentistry.

I am, Sirs, yours faithfully,

B. Faradar Giles, M.D. Durh.

Church-lane, Hornsey, N., Nov. 3rd, 1902.

\section{THE TUNING-FORK AS AN AID IN DIAGNOSIS.}

To the Editors of THE LANCET.

SIRs, - As the adequate treatment of disease is only possible when the diagnosis is correct, any aid to diagnosis is a matter of supreme importance. In Trre LANCET of Oct. 11th, p. 991, I read with interest Dr. G. M. de la Torre's article on unilateral pressure as a means of diagnosis in inflammatory conditions of the pulmonary organs. It has encouraged me to mention an additional aid which $I$ have lately used in my own practice and one which, it appears to me, is capable of considerable development. The tuning-fork has been long regarded as being of as much diagnostic importance to the aural surgeon as the stethoscope is to the physician. With the intelligent coöperation of the patient, however, it can be utilised to great advantage in general practice.

Patients suffering from pulmonary troubles-more especially in the earlier and convalescent stages-have frequently remarked that "when speaking they can hear or feel their own voices vibrating in the affected area," and this suggested to me experiments with the tuning-fork. I then found as an invariable rule that the vibrations of the tuning-fork were felt by the patient most distinctly when placed over a dull region, less distinctly when placed over an early or transitional dulness, and least over a healthy lung; I also found that with an intelligent patient it gave finer results than percussion. I further noticed that, though the differences were not so decidedly marked as in the preceding instances, on auscultating the back of the chest when the tuning-fork is placed over a corresponding part of the front of the chest it is more distinctly heard through healthy than through consolidated lung. This, too, was the reverse to the patient's own appreciation of the vibrations, the patient feeling them most over the dull part.

I have not yet had sufficient opportunity of testing the effect of the tuning-fork in cases of pleurisy with effusion, though in some slight cases which $I$ examined it appeared to me that the vibrations of the tuning-fork were less appreciated by the patient and by myself. This is a distinction to be noticed between this and the two preceding 